\title{
SOSIALISASI BUKU PANDUAN ERGONOMI "LEARNING FROM HOME" DARI PERHIMPUNAN ERGONOMI INDONESIA BAGI PESERTA DIDIK SEKOLAH DASAR DI KECAMATAN CIKEUSAL KABUPATEN SERANG
}

\author{
Deni Sunaryo, Yoga Adiyanto
}

Universitas Serang Raya

Corresponding Author, Email: denisunaryomm@gmail.com

\begin{abstract}
Ergonomics guidebook "Learning From Home" from the Indonesian Ergonomics Association is a learning resource for students included in the ergonomics guidebook "Learning From Home" from the Indonesian Ergonomics Association. The ergonomics guidebook "Learning From Home" from the Indonesian Ergonomics Association contains practical material, looks attractive, is easy to carry anywhere, and is able to make students focus on learning. Ergonomics guidebook "Learning From Home" from the Indonesian Ergonomics Association is packaged with a variety of interesting writings and pictures to motivate students to study the material contained in the ergonomics handbook "Learning From Home" from the Indonesian Ergonomics Association. So as for the purpose of developing this learning media by using the ergonomics guide book "Learning From Home" from the Indonesian Ergonomics Association is as an effort to increase students 'learning motivation because of its small shape and in order to increase students' learning motivation.
\end{abstract}

Keywords: Learning media, ergonomics handbook "Learning From Home" from the Indonesian Ergonomics Association, innovation

\begin{abstract}
Abstrak
Buku panduan ergonomi "Learning From Home" dari Perhimpunan Ergonomi Indonesia merupakan sumber belajar untuk Peserta Didik yang termasuk dalam buku panduan ergonomi "Learning From Home" dari Perhimpunan Ergonomi Indonesia. Pada buku panduan ergonomi "Learning From Home" dari Perhimpunan Ergonomi Indonesia berisikan materi-materi yang praktis, tampilannya menarik, mudah dibawa kemana pun, dan mampu membuat siswa terfokus dalam pembelajaran. Buku panduan ergonomi "Learning From Home" dari Perhimpunan Ergonomi Indonesia dikemas dengan berbagai tulisan dan gambar-gambar yang menarik sehingga menumbuhkan motivasi siswa untuk mempelajari materi yang ada pada buku panduan ergonomi "Learning From Home" dari Perhimpunan Ergonomi Indonesia. Maka adapun tujuan dari pengembangan media pembelajaran ini dengan menggunakan buku panduan ergonomi "Learning From Home" dari Perhimpunan Ergonomi Indonesia adalah sebagai upaya meningkatkan motivasi belajar peserta didik karena bentuknya yang kecil dan agar dapat meningkatkan motivasi belajar peserta didik.
\end{abstract}

Kata Kunci : Media pembelajaran, buku buku panduan ergonomi "Learning From Home" dari Perhimpunan Ergonomi Indonesia, inovasi

(C) 2020 Penerbit PS2PM FISIPKUM UNSERA

(C) 2020 Segala bentuk plagiarisme dan penyalahgunaan hak kekayaan intelektual akibat diterbitkannya artikel pengabdian masyarakat ini sepenuhnya menjadi tanggung jawab penulis

Deni Sunaryo, Yoga Adiyanto. Sosialisasi Buku Panduan Ergonomi "Learning From Home" dari Perhimpunan Ergonomi Indonesia Bagi Peserta Didik Sekolah Dasar di Kecamatan Cikeusal Kabupaten Serang 


\section{Pendahuluan}

Kecamatan Cikeusal kabupaten Serang Provinsi Banten memiliki 17 desa yang terdiri dari Desa Bantar Panjang, Cilayang, Cilayang Guha, Cimaung, Dahu, Gandayasa, Harundang, Katulisan, Mongpok, Panosogan, Panyabrangan, Sukamaju, Sukamenak, Sukaraja, Sukarame, dan Sukaratu serta Desa Cikeusal yang menjadi pusat ibukota dari Kecamatan Cikeusal. Kondisi Cikeusal pun dulu sangat memprihatinkan, mulai dari infrastrukur yang buruk seperti akses jalan rayanya yang rusak hingga kondisi masyarakat yang memiliki tingkat pendidikan yang rendah dan kurangnya pendidikan moral bagi para remaja Cikeusal dalam lingkungan masyarakat. Selain itu, Cikeusal pun terkenal dengan daerahnya para 'jawara' yang memiliki stigma negatif dalam pandangan masyarakat umum.

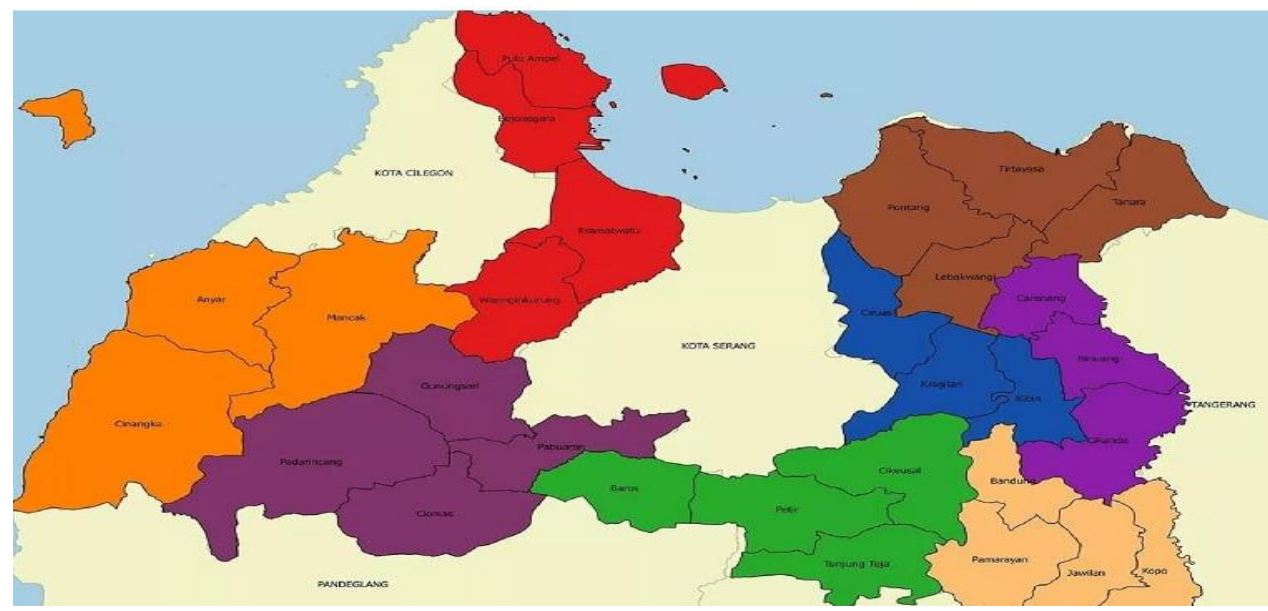

\section{Gambar 1 Peta Kabupaten Serang Provinsi Banten}

Jumlah penduduk di kecamatan cikeusal 68.652 orang (data BPS tahun 2018) dengan rincian sebagai berikut usia 0-4 tahun sebanyak 7036 orang, usia 5-9 tahun sebanyak 7276 orang, usia 10-14 tahun sebanyak 73,55 orang, dan usia 15-19 tahun sebanyak 6182, serta sisanya adalah usia diatas 19 tahun. 


\section{Usia Penduduk Kec. Cikeusal Kab. Serang}
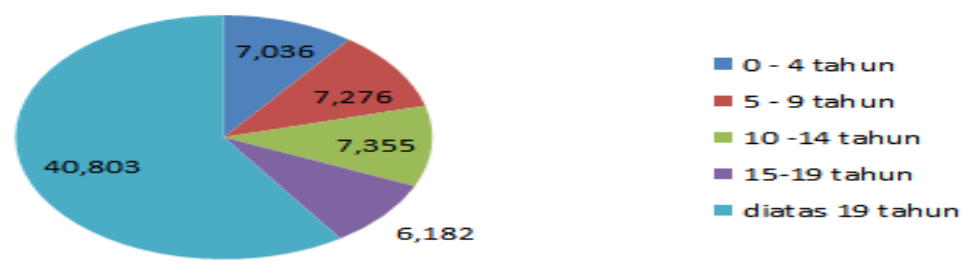

\section{Gambar 2. Usia Penduduk di Kecamatan Cikeusal Kabupaten Serang}

Sekolah dasar di kecamatan cikeusal

97\% adalah milik pemerintah atau
Sekolah Dasar Negeri dengan rincian

sekolah seperti pada tabel di bawah ini:

Tabel 1. Daftar Sekolah di kecamatan Cikeusal Kabupaten Serang

\begin{tabular}{|c|c|c|c|}
\hline No & NAMA SEKOLAH DASAR & ID SEKOLAH & ALAMAT \\
\hline 1 & SD NEGERI BANTARPANJANG & 20605516 & Kp, Dahu \\
\hline 2 & SD NEGERI BOJONG NEROS & 20606030 & Kp. Bojong Neros \\
\hline 3 & SD NEGERI CADAS NGAMPAR & 20606032 & Kp. Cadas Ngampar \\
\hline 4 & SD NEGERI CIBOGO & 20606061 & CIBOGO \\
\hline 5 & SD NEGERI CIKASAP & 20606021 & Kp. Cikasap \\
\hline 6 & SD NEGERI CIKEUSAL 1 & 20606025 & Kp. Sukaratu \\
\hline 7 & SD NEGERI CIKEUSAL 2 & 20606026 & Kp. Cirogol \\
\hline 8 & SD NEGERI CIKEUSAL 3 & 20606027 & Kp. Pasir Menyan \\
\hline 9 & SD NEGERI CILAYANG 1 & 20606016 & Kp. Teblongan \\
\hline 10 & SD NEGERI CILAYANG 2 & 20606017 & Cikeusal \\
\hline 11 & SD NEGERI CILAYANG 3 & 20606029 & Kp. Katupang Jati \\
\hline 12 & SD NEGERI CILAYANGGUHA & 20606121 & Kp. Pasir Laban \\
\hline 13 & SD NEGERI CIMAUNG 1 & 20606140 & Kp. Cimaung \\
\hline 14 & SD NEGERI CIMAUNG 2 & 20606141 & Kp. Cimaung \\
\hline 15 & SD NEGERI CIMAUNG 3 & 20606142 & Kp. Cikeusal \\
\hline 16 & SD NEGERI CIMAUNG 4 & 20606133 & Kp. Bangkong \\
\hline 17 & SD NEGERI DAHU & 20606118 & Kp. Pasirmanggu \\
\hline 18 & SD NEGERI GANDAYASA & 20605859 & Kp. Rangkaspanjang \\
\hline 19 & SD NEGERI HARUNDANG & 20605869 & Kp. Harundang \\
\hline 20 & SD NEGERI INPRES CIKEUSAL & 20605873 & Kp. Cikeusal Lor Rt/Rw $09 / 02$ \\
\hline 21 & SD INPRES SUKAMAJU & 20605874 & Kp. Sukamaju \\
\hline 22 & SD NEGERI JEGOG & 20605816 & Kp. Jegog \\
\hline 23 & SD NEGERI KATULISAN & 20605970 & Kp. Kabayan \\
\hline 24 & SD NEGERI KEDUNGCINDE & 20605905 & Kp. Kedungcinde \\
\hline 25 & SD NEGERI MONGPOK 1 & 20604887 & Kp.Ciagel \\
\hline 26 & SD NEGERI MONGPOK 2 & 20604889 & Kp. Rancalayung \\
\hline 27 & SD NEGERI MONGPOK 3 & 20604891 & Kp. Sampih Rt.17/04 \\
\hline 28 & SDN PABUARAN & 20616358 & Kp. Pabuaran Ds. Cimaung Kec. Cikeusal \\
\hline 29 & SD NEGERI PANOSOGAN 1 & 20604987 & Kp. Pasir Muncang \\
\hline зо & SD NEGERI PANOSOGAN 2 & 20604988 & Kp. Ranca Serang \\
\hline 31 & SD NEGERI PANYABRANGAN & 20604994 & JL. SIMPANG TIGA \\
\hline 32 & SD NEGERI PASIR & 20604735 & KP. PASIR DS SUKAMAJU \\
\hline 33 & SD NEGERI PASIR GADUNG & 20604742 & KP. PASIR GADUNG \\
\hline 34 & SD NEGERI PASIR KADUSIRUNG & 20604724 & Kp. Maja \\
\hline 35 & SD NEGERI PASIR MALANG & 20604725 & Kp. Pasirmalang \\
\hline 36 & SD NEGERI PASIRMANGGU & 20604726 & JI. KH. A. Gozali Kp. Pasirmanggu \\
\hline 37 & SD NEGERI RANCADADAP & 20604713 & Kp. Rancadadap \\
\hline 38 & SD NEGERI SEBA & 20604824 & Kp. Liang Landak \\
\hline 39 & SD NEGERI SUKAMAJU & 20605279 & KP. PASIR MANGGU \\
\hline 40 & SD NEGERI SUKAMENAK & 20605297 & Kp. Nyawana \\
\hline 41 & SD NEGERI SUKARATU & 20605298 & Kp. Pabuaran \\
\hline 42 & SD NEGERI TANCANG & 20605249 & Kp. Tancang \\
\hline 43 & SD NEGERI TURUNBALES & 20605377 & Kp. Turunbales \\
\hline
\end{tabular}

Deni Sunaryo, Yoga Adiyanto. Sosialisasi Buku Panduan Ergonomi "Learning From Home" dari Perhimpunan Ergonomi Indonesia Bagi Peserta Didik Sekolah Dasar di Kecamatan Cikeusal Kabupaten Serang 
Pendidikan sangat penting karena dengan adanya pendidikan maka akan lahir suatu generasi yang berpengetahuan luas dan berketerampilan. Pendidikan merupakan usaha sadar untuk menumbuh kembangkan potensipotensi yang ada dalam diri manusia melalui kegiatan pengajaran. Pendidikan diselenggarakan untuk memberikan pencerahan dan perubahan secara signifikan pada peserta didik. Pendidikan berperan penting dalam peningkatan kualitas Sumber Daya Manusia (SDM) yaitu menjadikan manusia menjadi insan yang beriman, mandiri, cerdas, maju, terampil, berpengetahuan luas, aktif, kreatif, bertanggung jawab, dan produktif.

Maka untuk mewujudkan itu semua perlu adanya motivasi belajar yang tinggi bagi siswa untuk dapat menjadi siswa yang mempunyai EQ dan IQ yang tinggi. Motivasi merupakan salah satu faktor yang dapat meningkatkan kualitas pembelajaran, karena akan belajar dengan sungguh-sungguh apabila memiliki motivasi yang tinggi (Mulyasa,2012). Sedangkan untuk jumlah siswa Sekolah Dasar Negri dapat dilihat pada Tabel dibawah ini

Tabel. 2 Daftar Siswa Sekolah Dasar Negri di Kecamatan Cikeusal Kabupaten Serang

\begin{tabular}{|c|c|c|c|c|c|c|}
\hline \multirow{2}{*}{$\begin{array}{l}\text { Desa/kefurahan } \\
\text { namage/Subdistrict }\end{array}$} & \multicolumn{2}{|c|}{$\begin{array}{l}\text { Sekolah } \\
\text { School }\end{array}$} & \multicolumn{2}{|c|}{$\begin{array}{l}\text { Guru } \\
\text { Teocher }\end{array}$} & \multicolumn{2}{|c|}{$\begin{array}{l}\text { Murid } \\
\text { Stendent }\end{array}$} \\
\hline & $\begin{array}{l}\text { Negeri } \\
\text { State }\end{array}$ & $\begin{array}{l}\text { Swrasta } \\
\text { Primate }\end{array}$ & $L / M$ & $P / F$ & $2 / M$ & $P / F$ \\
\hline (1) & (2) & (3) & (4) & (5) & (6) & (7) \\
\hline 1. Panyabrangan & 2 & - & 13 & 7 & 200 & 181 \\
\hline 2. Dathu & 4 & - & 12 & 29 & 335 & 276 \\
\hline 3. Bantar Pamjang & 2 & - & 9 & 12 & 128 & 97 \\
\hline 4. Katulisan & 3 & - & 13 & 20 & 229 & 201 \\
\hline 5. Panosogan & 2 & - & $\mathbf{8}$ & 14 & 166 & 160 \\
\hline 6. Cikeusat & 4 & - & 13 & 24 & 278 & 269 \\
\hline 7. Sukamaju & $=$ & - & 6 & 15 & 201 & 176 \\
\hline 8. Harundang & 2 & & 12 & 12 & 231 & 194 \\
\hline 9. Gandayasa & 4 & & 20 & 20 & 372 & 339 \\
\hline 10. Mongpok & 3 & - & 16 & 22 & 315 & 340 \\
\hline 11. Sukarame & 2 & - & 13 & 13 & 176 & 179 \\
\hline 12. Cilayang & 3 & - & 16 & 22 & 389 & 360 \\
\hline 13. Sukaratu & 3 & - & 18 & 17 & 241 & 252 \\
\hline 14. Sukamenak & 3 & - & 14 & 20 & 349 & 265 \\
\hline 15. Cimaung & 2 & & 16 & 13 & 294 & 258 \\
\hline 16. Sukaraja & 2 & - & 6 & 19 & 181 & 171 \\
\hline 17. Cilayang Guha & 1 & - & 5 & 8 & 117 & 106 \\
\hline Cikeusal & 44 & - & 210 & 287 & 4202 & 3824 \\
\hline
\end{tabular}

Deni Sunaryo, Yoga Adiyanto. Sosialisasi Buku Panduan Ergonomi "Learning From Home" dari Perhimpunan Ergonomi Indonesia Bagi Peserta Didik Sekolah Dasar di Kecamatan Cikeusal Kabupaten Serang 
Salah satu upaya dalam hal peningkatan pengajaran yang di lakukan oleh guru atau orang tua selama di rumah adalah adanya variasi atau inovasi dalam belajar. Maka melalui pengabdian kepada masyarakat untuk dapat memvariasikan atau inovasi dalam setiap kegiatan pembelajaran. Salah satu masalah yang timbul dalam pembelajaran di rumah adalah kurangnya inovasi pembelajaran dalam menerapkan pembelajaran kooperatif di rumah. Maka dengan adanya masalah yang di hadapi oleh guru maupun orang tua maka dapat disimpulkan untuk melakukan pengabdian masyarakat dengan memberikan sosialisasi buku panduan ergonomi "Learning From Home" dari Perhimpunan Ergonomi Indonesia guna meningkatkan motivasi belajar siswa. Salah satu upaya dalam meningkatkan motivasi belajar siswa adalah dengan menggunakan media pembelajaran, atau model model pembelajaran kooperatif untuk merangsang siswa belajar, salah satunya adalah dengan menggunakan media pembelajarn dengan menggunakan buku panduan ergonomi "Learning From Home" dari Perhimpunan Ergonomi Indonesia. buku panduan ergonomi "Learning From Home" dari Perhimpunan Ergonomi Indonesia merupakan buku literatur yang dikembangkan oleh para ahli ergonomidi Indonesia. Maka dengan adanya menggunakan buku panduan ergonomi "Learning From Home" dari Perhimpunan Ergonomi Indonesia untuk meningkatkan motivasi belajar siswa ini akan memudahkan siswa dalam belajar, sehingga harapannya dengan adanya media pembelajaran dapat meningkatkan dan mengarahkan perhatian anak sehingga dapat menimbulkan motivasi belajar, interaksi dengan lingkungan, dan kemandirian belajar siswa (Azhar Arsyad, 2011). 
Salah satu media pembelajaran yang dapat digunakan sebagai solusi dalam mengatasi rendahnya motivasi belajar siswa dan kenyamanan siswa dalam belajar adalah pengembangan media pembelajaran berupa buku panduan ergonomi “Learning From Home" dari Perhimpunan Ergonomi Indonesia yang sangat berguna untuk meningkatkan motivasi belajar siswa.

Pada buku panduan ergonomi "Learning From Home" dari Perhimpunan Ergonomi Indonesia berisikan materi-materi yang praktis, tampilannya menarik, mudah dibawa kemana pun, dan mampu membuat siswa terfokus dalam pembelajaran. buku panduan ergonomi "Learning From Home" dari Perhimpunan Ergonomi Indonesia dikemas dengan berbagai tulisan dan gambar-gambar yang menarik sehingga menumbuhkan motivasi siswa untuk mempelajari materi yang ada pada buku panduan ergonomi "Learning From Home" dari Perhimpunan Ergonomi Indonesia.

\section{Dalam Pengabdian Kepada} Masyarakat ini yang menjadi objek adalah peserta didik, orang tua, keluarga, khususnya adalah para dewan guru yang akan di berikan sosialisasi bagaimana meningkatkan motivasi belajar siswa denggan menggunakan media pembelajaran melalui buku panduan ergonomi "Learning From Home" dari Perhimpunan Ergonomi Indonesia. Berdasarkan analisis situasi dapat diidentifikasikan beberapa permasalahan yang di hadapi oleh mitra, adalah sebagai berikut:

- Pada dewan guru kurang dapat menggunakan media pembelajaran dengan baik.

- Belum pernah adanya pengetahuan dan sosialisasi tentang buku panduan ergonomi “Learning From Home" dari Perhimpunan Ergonomi Indonesia yang di berikan oleh dinas pendidikan atau instansi yang terkait. 
- Motivasi belajar siswa yang menurun karena kurang adanya inovasi dari guru.

- Media pembelajaran agae siswa nyamanbelajar selama dirumah salah satunya adalah dengan menggunkan buku panduan ergonomi "Learning From Home" dari Perhimpunan Ergonomi Indonesia.

\section{Metode}

Metode kegiatan ini berupa pelatihan kepada para orang tua, guru maupun keluarga. Setelah diberi sosialisasi dan pelatihan penggunaan media pembelajaran dalam buku panduan ergonomi "Learning From Home" dari Perhimpunan Ergonomi Indonesia dalam meningkatkan dan memberikan kenyamanan sehingga menghasilkan kualitas hasil belajar siswa di Sekolah Dasar Negri yang ada di kecamatan Cikeusal yang lebih baik, selanjutnya mereka dibimbing untuk menerapkan buku panduan ergonomi "Learning
From Home" dari Perhimpunan Ergonomi Indonesia tersebut dalam proses pembelajaran di rumah. Berikut ini adalah tahapan pelatihan yang dilakukan:

1) Tahap Persiapan, Tahap persiapan yang dilakukan meliputi :

- Survey

- Pemantapan dan penetuan lokasi dan sasaran

- Penyusunan bahan/materi pelatihan, yang meliputi: penggunaan media dalam pembelajaran dan buku panduan ergonomi "Learning From Home" dari Perhimpunan Ergonomi Indonesia

2) Tahap Pelaksanaan Pelatihan, Tahap pelaksanaan pelatihan dilakukan persiapan. Dalam tahap ini dilakukan pertama, penjelasan tentang Media pembelajaran, sesi pelatihan ini menitik beratkan pada pemberian penjelasan dalam buku panduan ergonomi “Learning From Home" dari Perhimpunan 
Ergonomi Indonesia untuk memotivasi orang tua, guru, peserta didik, dan keluarga agar mau menerapkan dan menanamkannya serta dapat meningkatkan motivasi siswa dalam belajar.

3) Metode Sosialisasi, Untuk melaksanakan kegiatan tersebut digunakan beberapa metode sosialisasi, yaitu:

- Metode Ceramah Interaktif

- Metode Tanya Jawab Metode tanya jawab sangat penting bagi para peserta pelatihan, baik di saat menerima penjelasan tentang media pembelajarn dan buku panduan ergonomi "Learning From Home" dari Perhimpunan Ergonomi Indonesia saat mempraktekkannya.

4) Metode Simulasi, Metode simulasi ini sangat penting diberikan kepada para peserta pelatihan sederhana untuk memberikan kesempatan mempraktekan materi pelatihan yang diperoleh. Harapannya peserta pelatihan akan benar-benar menguasai materi pelatihan yang diterima, mengetahui tingkat kemampuannya menerapkan kegiatan pelatihan pelaksanaan dari buku panduan ergonomi "Learning From Home" dari Perhimpunan Ergonomi Indonesia dan kemudian mengidentifikasi kesulitankesulitan serta menambah motivasi siswa untuk belajar.

Adapun metode pendekatan yang di lakukan dalam upaya kegiatan Pengabdian Kepada Masyarakat ini adalah sebagai berikut:

- Menjelaskan latar belakang dan tujuan program yang akan diterapkan.

- Memberikan motivasi dan dukungan kepada para orang tua, keluarga, guru serta para peserta didik dalam upaya pentingnya penggunaan buku panduan ergonomi "Learning From Home" dari Perhimpunan Ergonomi 
Indonesia, karena dengan adanya buku panduan ergonomi "Learning From Home" dari Perhimpunan Ergonomi Indonesia tentu akan memudahkan siswa untuk belajar lebih nyaman lagi nantinya.

Sejalan dengan hal tersebut, ada beberapa metode yang akan di kembangkan untuk memposisikan para orang tua, guru, peserta didik, dan keluarga yang mengikuti pelatihan Pengabdian Kepada Masyarakat ini, Hal ini perlu dilakukan agar mereka tidak hanya sekedar objek yang hanya pasif menerima pelatihan tetapi ikut berpartisipasi aktif untuk menjalankan program ini dengan mengembangkannya agar tujuan dari program ini tercapai. Metode yang dilakukan adalah sebagai berikut: Pertama pendekatan partisipatif dan dialogis, yaitu dengan cara menghubungi para kepala Sekolah, dan Dewan Guru Sekolah Dasar Negri di kecamatan Cikeusal kabupaten Serang terlebih dahulu. Kedua pengumpulan para guru-guru untuk dapat mengikuti pelatihan akan pentingnya penggunaan media belajar dengan menggunakan buku buku panduan ergonomi "Learning From Home" dari Perhimpunan Ergonomi Indonesia.

Selanjutnya adalah kegiatan musyawarah antara peserta pelatihan dengan tim Pengabdian Kepada masyarakat, Musyawarah disini yaitu tentang Program pelatihan yang akan di laksanakan serta kendala-kendala yang dimungkinkan akan timbul dalam pelaksanaan kegiatan pelatihan ini, sehingga dalam musyawarah ini bisa mendapatkan solusi akan kendala tersebut. Setelah musyawarah tersebut, kita sebagai tenaga pelaksana Pengabdian Kepada Masyarakat akan mendampingi serta memberikan pelatihan kepada khalayak sasaran dalam memberikan pelatihan tersebut.

\section{Pembahasan}

Permasalahan yang muncul adalah belum adanya sosialisasi dan pelatihan 
yang di berikan kepada para guru tentang adanya bagaimana upaya meningkatkan motivasi belajar siswa dengan menggunkan media pembelajaran dengan mengggunakan buku buku panduan ergonomi "Learning From Home" dari Perhimpunan Ergonomi Indonesia . Media pembelajaran merupakan sarana guru dalam menyampaikan berbagai bahan dan materi pelajaran kepada siswa agar lebih mudah disampaikan. Media pembelajaran sudah mulai dikembangkan oleh para guru dari tingkat pendidikan dasar hingga menengah. Dalam kegiatan belajar mengajar media mempunyai peran penting karena membuat proses komunikasi antara guru dengan siswa terjalin secara optimal. Selain itu, siswa akan merasa senang dalam mengikuti pembelajaran sehingga siswa dapat lebih mudah menangkap materi pelajaran. Penggunaan media pembelajaran dikemas secara kreatif, inovatif, menarik, dan disesuaikan dengan kebutuhan siswa agar dapat mencapai tujuan pembelajaran. Pemanfaatan media pembelajaran sedapat mungkin dikemas lebih menarik agar siswa mampu memahami materi dengan mudah dan cepat. Dengan adanya media pembelajaran dapat meningkatkan dan mengarahkan perhatian anak sehingga dapat menimbulkan motivasi belajar, interaksi dengan lingkungan, dan kemandirian belajar siswa (Azhar Arsyad, 2011: 26). Salah satu media pembelajaran yang dapat digunakan sebagai solusi dalam mengatasi rendahnya motivasi belajar siswa adalah pengembangan media pembelajaran berupa buku buku panduan ergonomi "Learning From Home" dari Perhimpunan Ergonomi Indonesia. Buku buku panduan ergonomi "Learning From Home" dari Perhimpunan Ergonomi Indonesia merupakan sumber belajar untuk siswa yang termasuk dalam media cetak. Pada buku buku panduan ergonomi 
“Learning From Home" dari Perhimpunan Ergonomi Indonesia berisikan materi- materi yang praktis, tampilannya menarik, mudah dibawa kemana pun, dan mampu membuat siswa terfokus dalam pembelajaran. Buku buku panduan ergonomi "Learning From Home" dari Perhimpunan Ergonomi Indonesia dikemas dengan berbagai tulisan dan gambar- gambar yang menarik sehingga menumbuhkan motivasi siswa untuk mempelajari materi yang ada pada buku buku panduan ergonomi "Learning From Home" dari Perhimpunan Ergonomi Indonesia. Maka adapun tujuan dari pengembangan media pembelajaran ini dengan menggunakan buku buku panduan ergonomi "Learning From Home" dari Perhimpunan Ergonomi Indonesia adalah sebagai upaya meningkatkan motivasi belajar siswa karena bentuknya yang kecil dan agar dapat meningkatkan motivasi belajar siswa. Dengan adanya media pembelajaran dengan menggunakan buku buku panduan ergonomi "Learning From Home" dari Perhimpunan Ergonomi Indonesia ini maka di harapkan akan memudahkan siswa dan para guru dalam menerima pembelajaran, maka dengan adanya buku panduan ergonomi "Learning From Home" dari Perhimpunan Ergonomi Indonesia ini akan dapat meningkatkan motivasi belajar siswa. Oleh karena itu, Pelaksanaan PKM ini untuk mencoba menawarkan penyelesaian masalah sekolah tersebut dengan melaksanakan sosialisasi dan pelatihan dalam memotivasi belajar siswa dengan menggunakan media pembelajaran melalui buku buku panduan ergonomi "Learning From Home" dari Perhimpunan Ergonomi Indonesia, maka dengan adanya buku buku panduan ergonomi "Learning From Home" dari Perhimpunan Ergonomi Indonesia ini nantinya akan memudahkan siswa dalam menerima materi pelajaran karena bentuknya 
buku buku panduan ergonomi “Learning From Home" dari Perhimpunan Ergonomi Indonesia ini bentuknya kecil dan dapat di bawa kemana saja dan bisa di letakkan di buku panduan ergonomi "Learning From Home" dari Perhimpunan Ergonomi Indonesia karena bentuknya yang kecil dan ada berupa digital literasinya. Maka dengan adanya sosialisasi ini hendaknya para guru dapat memberikan arahan kepada siswanya untuk dapat membuat buku buku panduan ergonomi "Learning From Home" dari Perhimpunan Ergonomi Indonesia sendiri, atau buku buku panduan ergonomi "Learning From Home" dari Perhimpunan Ergonomi Indonesia yang telah di sediakan oleh guru, guna menunjang keberlangsunggan belajar dalam proses kegiatan belajar mengajar. Pengembangan perangkat merupakan suatu lingkaran yang kontinum. Tiaptiap langkah pengembangan berhubungan langsung dengan aktivitas revisi. Pengembangan perangkat dapat dimulai dari titik mana pun di dalam siklus tersebut. Model pengembangan sistem pembelajaran ini memiliki unsur-unsur pengembangan perangkat pembelajaran:

1. Mengidentifikasi Masalah Pembelajaran. Tahap ini betujuan untuk mengidentifikasi kesenjangan antara tujuan menurut kurikulum yang berlaku dengan fakta yang terjadi di lapangan baik yang menyangkut model, pendekatan, metode, teknik maupun strategi yang digunakan guru.

2. Analisis Siswa. Analisis ini dilakukan untuk mengetahui tingkah laku awal dan karateristik siswa yang meliputi ciri, kemampuan dan pengalaman baik individu maupun kelompok.

3. Analisis Tugas. Analisis tugas merupakan kumpulan prosedur untuk menentukan isi suatu 
pengajaran, analisis konsep, analisis

pemrosesan informasi, dan analisis

prosedural yang digunakan untuk

memudahkan pemahaman dan

penguasaan tentang tugas-tugas belajar dan tujuan pembelajaran

yang dituangkan dalam bentuk

Rencana Program Pembelajaran

(RPP) dan lembar kegiatan siswa

(LKS)

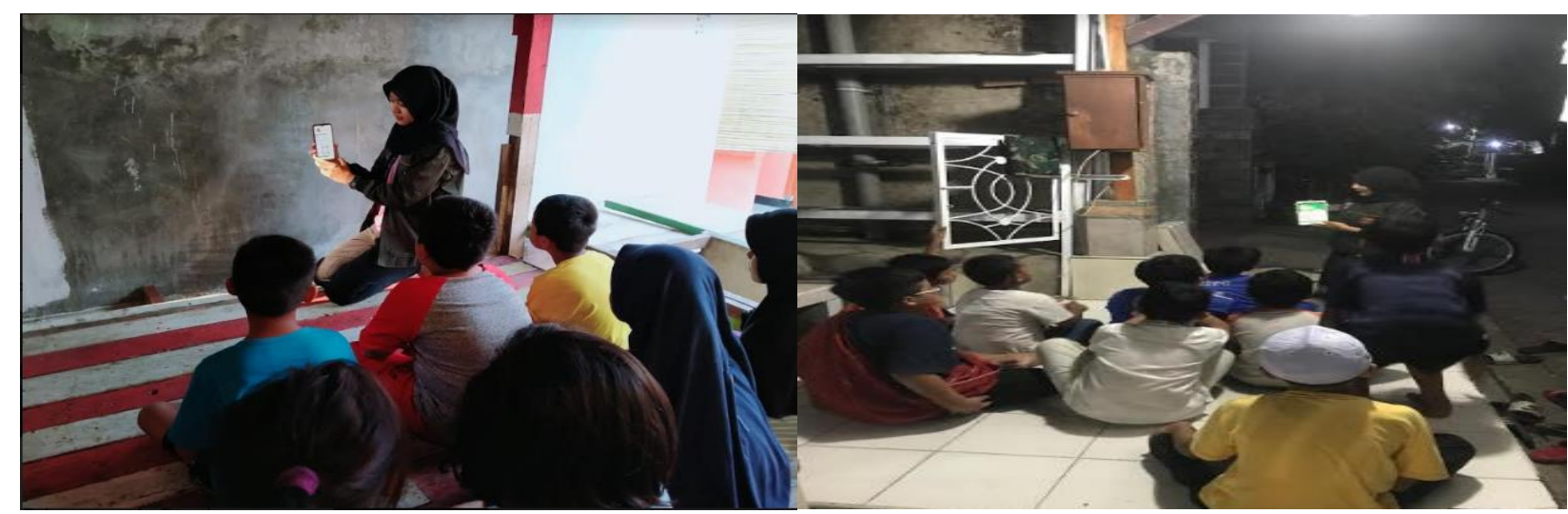

Gambar 2 . Pembelajaran buku panduan ergonomi “Learning From Home” dari Perhimpunan Ergonomi Indonesia saat siang hari dan petang hari

4. Merumuskan Indikator Analisis indikator berfungsi sebagai alat untuk mendesain kegiatan pembelajaran, kerangka kerja dalam merencanakan mengevaluasi hasil belajar siswa, dan panduan siswa dalam belajar.

5. Penyusunan Instrumen Evaluasi. Penyusunan tes hasil belajar bertujuan untuk mengukur ketuntasan indikator dan kemampuan siswa setelah melakukan pembelajaran
6. Strategi Pengembangan. Pada tahap ini dilakukan pemilihan strategi belajar mengajar yang sesuai dengan tujuan, meliputi: pemilihan model, pendekatan, metode, pemilihan format, yang dipandang mampu memberikan pengalaman yang berguna untuk mencapai tujuan pembelajaran.

7. Pemilihan Media atau Sumber Belajar. Pemilihan media dan sumber- sumber belajar harus dipilih dan disiapkan dengan hati-

Deni Sunaryo, Yoga Adiyanto. Sosialisasi Buku Panduan Ergonomi "Learning From Home" dari Perhimpunan Ergonomi Indonesia Bagi Peserta Didik Sekolah Dasar di Kecamatan Cikeusal Kabupaten Serang 
hati, agar dapat memenuhi tujuan pembelajaran.

8. Pelayanan Pendukung. Layanan pendukung meliputi kebijakan kepala sekolah, tim guru, petugas Tata Usaha (TU), laboran, dan pustakawan

9. Evaluasi Formatif dan Sumatif Evaluasi formatif berfungsi sebagai pemberi informasi kepada pengajar atau tim pengembang seberapa baik program telah terlaksana dalam mencapai sasaran, sedangkan evaluasi sumatif berfungsi untuk mengukur tingkat pencapaian tujuan-tujuan utama pada akhir pembelajaran.

10. Revisi Perangkat Pembelajaran Kegiatan ini dimaksudkan untuk mengevaluasi dan memperbaiki rancangan yang dibuat.

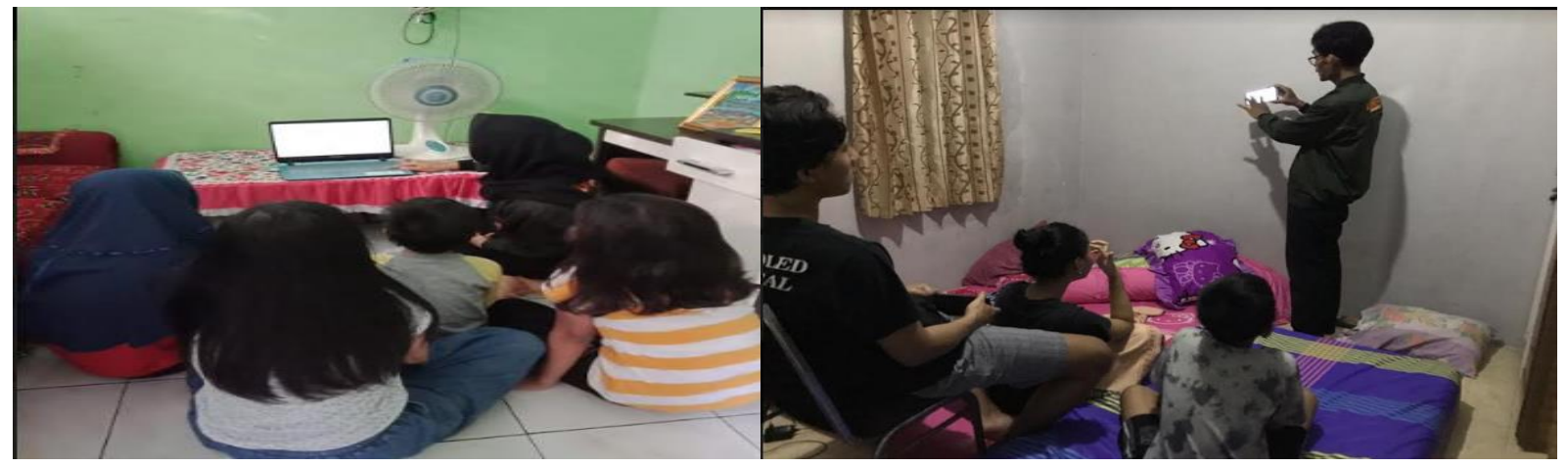

Gambar 3 . Pembelajaran buku panduan ergonomi "Learning From Home" di Lingkungan Keluarga dan setelah Mengaji di Mesjid

\section{Simpulan}

Dalam pengabdian ini dapat disimpulkan bahwa kegiatan ini sangat aplikatif dan memenuhi unsur informasi yang mudah untuk dijelaskan kepada siswa selama di rumah dan lingkungan rumah, dengan antusias berbagai pertanyaan dari berbagai siswa dan orang tua. Keikutsertaan antara guru dan orang tua serta keluarga bahwa buku yang diajarkan ini memenuhi syarat dan nyaman untuk di sebarluaskan kepada pihak lain.

Deni Sunaryo, Yoga Adiyanto. Sosialisasi Buku Panduan Ergonomi "Learning From Home" dari Perhimpunan Ergonomi Indonesia Bagi Peserta Didik Sekolah Dasar di Kecamatan Cikeusal Kabupaten Serang 


\section{Referensi}

Arsyad Azhar. (2011). Media Pembelajaran. Jakarta: Rajawali Pers. Asep Jihad, dkk. (2009). Evaluasi Pembelajaran. Jakarta: MultiPress.

Dina Indriana. (2011). Ragam Alat Bantu Media Pengajaran. Yogyakarta: DIVA Press.

Eko Putro Widoyoko. (2013). Teknik Penyusunan Instrumen Penelitian. Yogyakarta: Pustaka Pelajar.

Endang Mulyatiningsih. (2012). Metode

Penelitian Terapan (Bidang Pendidikan), Bandung: Alfabeta.

Hamzah, B.Uno, dkk. (2013). Teori

Motivasi dan Pengukurannya (Analisis dibidang Pendidikan). Jakarta: Bumi Aksara.

Hizair. (2013). Kamus Lengkap Bahasa Indonesia. Jakarta: Tamer.

Hujair AH Sanaky. (2013). Media Pembelajaran Interaktif Inovatif. Yogyakarta: Kaukaba Dipantara.
Martinis Yamin. (2007). Kiat Membelajarkan Siswa. Jakarta: Gaung Persada Press.

Mohamad Ali. (2013). Penelitian Kependidikan: Prosedur \& Strategi. Bandung: Angkasa

Mulyasa. (2013). Implementasi Kurikulum Tingkat Satuan Pendidikan, Kemandirian Guru dan Kepala Sekolah. Jakarta: Bumi Aksara.

Nana Syaodih Sukmadinata. (2013). Metode Penelitian Pendidikan. Bandung: PT. Remaja Rosdakarya.

NgalimPurwanto. (2006). Psikologi Pendidikan. Bandung: PT Remaja Rosdakarya.

Nurul Mar'atus Sholihah. (2015). “Pengembangan Buku Buku panduan ergonomi "Learning From Home" dari Perhimpunan Ergonomi Indonesia Akuntansi Sebagai Media Pembelajaran untuk Meningkatkan Motivasi Belajar Akuntansi Bagi Siswa 
Kelas XI Akuntansi di SMK Muhammadiyah 2 Yogyakarta Tahun Ajaran 2014/2015." Skripsi. Fakultas Ekonomi UNY.

Diambil dari: http://eprints. uny.ac.id/, pada tanggal 1 November 2015.

Oemar Hamalik. (2002). Psikologi Belajar dan Mengajar. Bandung: Sinar Baru Algensindo.

Peraturan Menteri Pendidikan dan Kebudayaan Nomor 32 Tahun 2013.

Rusman. (2012).Belajardan

Pembelajaran Berbasis Komputer. Bandung: Alfabeta.

Sardiman, AM. (2012). Interaksi danMotivasi Belajar Mengajar. Jakarta: Rajawali Pers.

Sudarwan Danim. (2010). Media Komunikasi Pendidikan. Jakarta: PT Bumi Aksara.

Sugiyono. (2012).Metode Penelitian Pendidikan: Pendekatan Kuantitatif, Kualitatif, dan R\&D). Bandung:
Alfabeta.Suherman Rosyidi. (1996). Pengantar Teori Ekonomi. Jakarta: PT RajaGrafindo Persada. Suprihatiningrum Jamil. (2014). Strategi Pembelajaran:

Teori dan Aplikasi Jogjakarta: Ar-Ruzz Media.

Trianto. (2011). Mendesain Model Pembelajaran Inovatif-Progresif. Jakarta: PT Fajar Interpratama Mandiri.

Yulian Adi Setyono, Sukarmin Karmin, dan Daru Wahyuningsih. 2013. “Pengembangan Media Pembelajaran Fisika Berupa Buletin Dalam Bentuk Buku Buku panduan ergonomi "Learning From Home" dari Perhimpunan Ergonomi Indonesia untuk Pembelajaran Fisika Kelas VIII Materi Gaya Ditinjau Dari Minat Baca Siswa. Diambil dari: http://eprints. uns.ac.id/, pada tanggal 1 Nov 2015. 